Original Article

\title{
Comparison of the T10 and L4 paraspinal muscle activities over time during continuous computer work
}

\author{
WON-GYU Yoo ${ }^{1)}$ \\ 1) Department of Physical Therapy, College of Biomedical Science and Engineering, Inje University: \\ 607 Obangdong, Gimhae, Gyeongsangnam-do 621-749, Republic of Korea
}

\begin{abstract}
Purpose] This study compared the T10 and L4 paraspinal muscle activities over time during continuous computer work. [Subjects] Ten male workers participated in this study. [Methods] The T10 and L4 paraspinal muscle activities were measured using a surface EMG system after 0, 20, 40, and 80 minutes of continuous computer work. [Results] The T10 and L4 paraspinal muscle activities after 20 and 40 minutes were increased significantly compared with the initial values, while they were decreased significantly after 80 minutes compared with the initial readings. [Conclusion] This study suggests that workers using computers for short periods would benefit from back muscle stretching exercises due to increased tension in these muscles. For longer computer work, strengthening exercises would be more effective than stretching due to decreased back muscle activation.

Key words: Back muscle exercise, Computer user, Paraspinal muscles
\end{abstract}

(This article was submitted Apr. 13, 2015, and was accepted May 18, 2015)

\section{INTRODUCTION}

Several epidemiological studies have examined computer use as a cause of low back pain (LBP) and neck and shoulder pain $^{1,2)}$. In the sagittal plane, habitual poor posture includes forward head and flexed-relaxed postures ${ }^{3,4}$ ). Computer users readily adopt both of these positions due to the low muscle effort required, which places a greater load on passive paraspinal structures ${ }^{2,3)}$. Yoo et al. ${ }^{5}$ reported that the trunk flexion angle was decreased significantly immediately after shifting from the initial upright sitting posture to the cross-legged sitting posture, and significantly decreases were observed at 10, 20, and 30 minutes. Consequently, the static posture in visual display terminal workers results in an increased forward flexion sitting posture and increased static muscle tension in the shoulder and back regions ${ }^{6}$. When spinal structures, such as passive ligaments or active muscles, are stretched or flexed during sitting, reflexive muscle activity may be reduced, passive structures may be lengthened, and their tension may be reduced due to unsuitable stretching stimulation from the central nervous system $^{7)}$. This study compared the activities of the T10 and L4 paraspinal muscles over time $(0,20,40$, and 80 minutes $)$ during continuous computer work.

Corresponding author. Won-gyu Yoo (E-mail: won7y@inje. ac.kr)

(C2015 The Society of Physical Therapy Science. Published by IPEC Inc. This is an open-access article distributed under the terms of the Creative Commons Attribution Non-Commercial No Derivatives (by-ncnd) License $<$ http://creativecommons.org/licenses/by-nc-nd/3.0/>.

\section{SUBJECTS AND METHODS}

Ten male computer workers, none of whom had a history of disease or any problems with walking, volunteered to participate in the study. The average age, height, and weight of the subjects were $31.3 \pm 4.3$ years, $176.2 \pm 3.0 \mathrm{~cm}$, and $70.5 \pm 6.3 \mathrm{~kg}$, respectively. The study purpose and methods were explained to the subjects before their participation, and they provided informed consent according to the principles of the Declaration of Helsinki. The T10 and L4 paraspinal muscle activities were measured using a surface EMG system after $0,20,40$, and 80 minutes of continuous computer work. For the T10 and L4 paraspinal muscles, the electrodes were placed $2 \mathrm{~cm}$ lateral to the midline of the respective muscles. The ground electrode was positioned at the $\mathrm{C} 7$ process. Before attaching the electrodes, the skin was cleaned with sandpaper and alcohol. All of the procedures for electrode and kinematic marker placement were performed by the same investigator to reduce variability. Using two electrodes, the muscular signals were measured by applying a $100-1,000 \mathrm{~Hz}$ band-pass filter. The speed of a muscle signal could be measured at $1,000 \mathrm{~Hz}$. The analogue signal was converted to a digital signal with an analogue/digital (A/D) converter (NI USB-6009; National Instruments, Austin, TX, USA).

The computer workstation featured a 23 -inch monitor, a keyboard and mouse on a table, and a swivel chair with five wheels. To allow analysis of back muscle activities, the armrest and backrest were removed. Both the table and chair were adjustable in terms of height and were initially set to ensure that the elbows, hips, and knees were flexed at $90^{\circ}$. The keyboard and mouse were positioned frontally $30 \mathrm{~cm}$ from the trunk; the monitor was reclined by $20^{\circ}$; and the top of 
the display was set at eye level (standard sitting posture). All subjects performed selected computer work for 80 minutes using the workstation. The T10 and L4 paraspinal muscle activities were measured using a surface EMG system after 0, 20, 40, and 80 minutes of continuous computer work using the program Hansoft (Hansoft, Uppsala, Sweden). SPSS ver. 12.0 (SPSS, Chicago, IL, USA) was used to assess differences in the T10 and L4 paraspinal muscles over time (0, 20, 40 , and 80 minutes). Repeated measures one-way analysis of variance (ANOVA) was used to examine the significance of differences in measures. In all analyses, $p<0.05$ was taken to indicate statistical significance.

\section{RESULTS}

The T10 and L4 paraspinal muscle activities significantly increased after $20(24.8 \pm 10.2 \%$ and $23.4 \pm 9.1 \%$, respectively) and $40(26.3 \pm 15.2 \%$ and $28.6 \pm 11.8 \%)$ minutes compared with the initial values $(19.5 \pm 11.2 \%$ and $17.6 \pm 12.0 \%$, respectively) $(\mathrm{p}<0.05)$. However, the T10 and L4 paraspinal muscle activities were decreased significantly after 80 minutes $(16.7 \pm 8.2 \%$ and $13.9 \pm 9.3 \%)$ compared with those at 0,20 , and 40 minutes $(\mathrm{p}<0.05)$.

\section{DISCUSSION}

This study investigated the changes in T10 and L4 paraspinal muscle activities over time during 80 minutes of computer work. When lumbar and thoracic muscle activation levels decrease, passive tissues (ligaments, lumbodorsal fascia, etc.) of the spine may support the load moment ${ }^{8)}$. A prolonged load added to the ligaments of the lumbar spine may affect the lumbar spine, stimulate pain receptors, and eventually become a source of LBP in computer workers ${ }^{8,9)}$. In addition, prolonged flexion during sitting was found to result in redistribution of the nucleus within the annulus ${ }^{2)}$. Mork and Westgaard also suggested that constitutive exposure to a relaxed sitting posture exacerbates LBP in computer workers ${ }^{10)}$. Our results showed that the T10 and L4 paraspinal muscle activities were increased significantly after 20 and 40 minutes of computer work compared with the initial values, while they were decreased significantly after 80 minutes compared with those at 0,20 , and 40 minutes. Decreases in trunk muscle activity result in an increased load on the lumbar discs and ligaments ${ }^{2,11)}$. When the sitting posture changes from erect to slumped, postural muscle activity decreases, as the trunk posture supported by the passive paraspinal structures responds to gravity ${ }^{11)}$. This slumped sitting posture may cause strain, instability, or injury in the lumbopelvic region ${ }^{2)}$. Yoo reported that regular, passive exercises are effective at preventing LBP in computer users ${ }^{9}$. Impaired proprioception in sitting and standing positions can be related to $\mathrm{LBP}^{2,3)}$. This results suggest that workers using computers for short periods would benefit from back muscle stretching exercises due to increased tension in these muscles, while strengthening exercises would be more effective than stretching for long-term computer work, due to decreased back muscle activation.

\section{ACKNOWLEDGEMENT}

This work was supported by a grant from Research year of Inje University in 2014 (No. 20141331).

\section{REFERENCES}

1) Nakazawa $T$, Okubo $Y$, Suwazono $Y$, et al: Association between duration of daily VDT use and subjective symptoms. Am J Ind Med, 2002, 42: 421-426. [Medline] [CrossRef]

2) Neumann DA: Kinesiology of the musculoskeletal system. St. Louis: Mosby, 2002.

3) O'Sullivan P, Dankaerts W, Burnett A, et al.: Evaluation of the flexion relaxation phenomenon of the trunk muscles in sitting. Spine, 2006, 31: 2009-2016. [Medline] [CrossRef]

4) Yoo WG, Kim MH: Effect of different seat support characteristics on the neck and trunk muscles and forward head posture of visual display terminal workers. Work, 2010, 36: 3-8. [Medline]

5) Lee JH, Park SY, Yoo WG: Changes in craniocervical and trunk flexion angles and gluteal pressure during VDT work with continuous cross-legged sitting. J Occup Health, 2011, 53: 350-355. [Medline] [CrossRef]

6) Liao MH, Drury CG: Posture, discomfort and performance in a VDT task. Ergonomics, 2000, 43: 345-359. [Medline] [CrossRef]

7) Hashemirad F, Talebian S, Hatef B, et al.: The relationship between flexibility and EMG activity pattern of the erector spinae muscles during trunk flexion-extension. J Electromyogr Kinesiol, 2009, 19: 746-753. [Medline] [CrossRef]

8) Kuo YL, Tully EA, Galea MP: Video analysis of sagittal spinal posture in healthy young and older adults. J Manipulative Physiol Ther, 2009, 32: 210-215. [Medline] [CrossRef]

9) Yoo WG: Effect of resting in a chair, resting with range of motion exercises, and back strengthening exercises on pain and the flexion-relaxation ratio of computer workers with low back pain. J Phys Ther Sci, 2014, 26: 321-322. [Medline] [CrossRef]

10) Mork PJ, Westgaard RH: Back posture and low back muscle activity in female computer workers: a field study. Clin Biomech (Bristol, Avon), 2009, 24: 169-175. [Medline] [CrossRef]

11) Cholewicki J, McGill SM: Mechanical stability of the in vivo lumbar spine: implications for injury and chronic low back pain. Clin Biomech (Bristol, Avon), 1996, 11: 1-15. [Medline] [CrossRef] 